\title{
Configuration of wind farm in Kaberten region: wind potential and optimal capacity
}

\author{
Zergane Said $^{1} \cdot$ Rokbi Mansour $^{1}\left[\right.$ [ $\cdot$ Gesmia Seyfeddine ${ }^{2} \cdot$ Mehdi Mehdizadeh $^{3}$
}

Received: 26 August 2019 / Accepted: 31 October 2019 / Published online: 6 November 2019

(c) Springer Nature Switzerland AG 2019

\begin{abstract}
The configuration of a wind farm depends mainly on the wind potential and the disposition of the wind turbines in this park. The windiest site is the most favorable for a future installation of wind turbines for the production of electricity, also, in this same site, a too dense arrangement would lead to considerable of power losses under the effect of wake. In this context, it is presented a research work that consists of determining the installation conditions of a wind farm; evaluating the wind farm through measurements of wind speed and the location of wind turbines in the park to minimize the effect of wind turbine interference. In order to do this, an evaluation study of the wind potential for the implementation of a wind farm based on the quantification of the wind in speed and directions firstly proposed. Secondly, a method for optimizing the positioning of wind turbines in a wind power farm is used based on the introduction of the Jensen wake model and the application of the iterative pseudo-random distribution approach of the turbines in the site. Simulation results are presented and discussed using data from the Kaberten site in Algeria and the characteristics of the GAMESA G52 wind turbine.
\end{abstract}

Keywords Renewable energy · Wind farm · Wind turbine - Wake model · Pseudo-random numbers · Optimization

\section{List of symbols}

A Scale factor $(\mathrm{m} / \mathrm{s})$

$A_{R} \quad$ Wind farm area $\left(\mathrm{m}^{2}\right)$

$a \quad$ Integer called the germ

$b \quad$ Random integer

$C_{\text {ost }}$ Cost of wind installation

$C_{T} \quad$ Thrust coefficient

$D \quad$ Rotor diameter $(\mathrm{m})$

$f_{\text {cap }}$ Capacity factor

$f_{o p} \quad$ Optimal capacity factor

$f(V) \quad$ Wind speed frequency

$k$ Form factor

$m$ Divisor

mod Modulo operator

$N_{w t} \quad$ Number of turbines in wind farm

$N \quad$ Number of cells
$P \quad$ Turbine power (W)

$P_{\max }$ Maximum power (W)

$P_{\text {tot }} \quad$ Total power $(\mathrm{W})$

$r_{0} \quad$ Rotor radius $(\mathrm{m})$

$r \quad$ Wake radius at $x$ position $(\mathrm{m})$

$x \quad$ Wake downstream position $(\mathrm{m})$

$X(n) \quad$ Elements of pseudo-random sequence

$U \quad$ Upstream wind speed $(\mathrm{m} / \mathrm{s})$

$U_{m} \quad$ Average wind speed $(\mathrm{m} / \mathrm{s})$

$U_{x} \quad$ Wind seep in the wake $(\mathrm{m} / \mathrm{s})$

$Z \quad$ Hub height (m)

$Z_{0} \quad$ Ground roughness (m)

a Entrainement coefficient

$\sigma_{V} \quad$ Standard deviation

$\rho \quad$ Air density $\left(\mathrm{kg} / \mathrm{m}^{3}\right)$

Rokbi Mansour, rokbimansour@univ-msila.dz | ${ }^{1}$ Department of Mechanical Engineering, Faculty of Technology, University of M'sila, 28000 M'Sila, Algeria. ${ }^{2}$ University of Quebec, Montreal, Canada. ${ }^{3}$ Faculty of Mechanical and Energy Engineering, Shahid Beheshti University, Tehran, Iran. 


\section{Introduction}

In the last decades, the need for fossil energy resources, such as coal, oil and natural gas have been steadily rising, so that, their over exploitation has increased the challenges and dangers of climate changes. Global warming and air pollution are the consequences of the observed massive release of carbon dioxide linked to the consumption of these substances. To this end, today's society has a global tendency to use increasingly renewable energies. Among these, the wind energy is usually the less expensive than the other renewable energy resources in the world [1].

Wind energy is an alternative clean energy source, environmental friendly system, sustainable and does not produce greenhouse gases, compared to fossil fuel [2]. In terms of sustainable development, wind energy has seen a strong evolution through the installation of wind farms for the production of electrical energy. However, their returns depend primarily on the assessment of the wind farm and the proper location of turbines in the farm.

Under the wake's effect, a speed deficit leads to a reduction in power could be noted, this phenomenon is much more accentuated in the dense gathering of turbines in wind farms. To this end, a number of experimental and numerical studies have been carried out to evaluate the effects of the wake interference on the performance of the wind turbine [3-5].

Understanding of power losses and turbine wake interactions of a wind turbine alone is a crucial study to optimizing wind farm design. Using an experimental investigation, Adaramola et al. [3] have studied the wake interference effect on the performance of the wind turbine. They found that by applying an optimized yaw angle to the upstream turbine, an overall improvement in the power output by $12 \%$ could be observed. In the other hand, several analysis models and methods have been employed to identify the optimal location of wind turbines in the farms [6-8]. In the case of a wind farm, a reduction of energy production in all turbines can be mentioned because of a wind speed deficit at the downstream wind turbines (WTs). This reduction is due to the wake effect. Hence, it is necessary to minimize the wake losses by optimizing a wind farm layout design. One of the widely used analytical models is the model which is introduced by Jensen [9].

The first research study on Wind Farm Layout Optimization Problem (WFLOP) was developed by Mosetti et al. [6]. They used genetic algorithms to determine the positions of wind turbines that provide the maximum energy extraction with the minimum installation costs. Based on Mosetti's approach, Grady et al. [7] predicted the optimal wind farm placement of turbines. In other work, better optimizing results were obtained by Marmidis et al. [8] with introducing Monte Carlo simulation for wind turbines system. As a result of more demand for wind turbine installation, the WFLOP always remains among the most addressed topics for scientists and engineers in this area. Thanks to the wind farm layout optimization which can mitigate the power losses due to the wake interaction between turbines.

More recently, a framework for designing wind farm layouts, using surrogate wake models combined with hybrid optimization, which has been presented by Mahulja et al. [10]. The optimal number of turbines as well as their optimal locations were successfully found. Zergane et al. [11] proposed a new pseudo-random numbers generation method along with the Jensen linear wake model. They conclude that the proposed optimization method appears to be more suitable and noticeable enhancements on total power production, and which can be obtained in comparison with previous studies. Various optimizing algorithms have been applied to the wind farm layout optimization problem. Pérez et al. [12] have adopted a mathematical programming method for the offshore wind farm optimization. To maximize the electric power production from offshore wind farms, authors have used combined heuristic and nonlinear mathematical programming techniques. For prediction the wind farm power production, Wang et al. [13] adopted three different analytical wake models (PARK model, Larsen model and B-P model).

The efficiency of analytical methods is also studied to increase the performance of energy production with several hub heights. Benmbarek et al. [14] have used the GH Wind Farmer and Wind Atlas Analysis and Application Program (WAsP) software in order to optimize the location of ten turbines in the site of Kaberten. Authors explain the increasing significance of net energy in every wind generator by the decrease of the trail effect in the park. Gharbia et al. [15] have also applied the WAsP software for predicting the feasibility of erecting a wind farm with installed capacity of $120 \mathrm{MW}$ in a suitable location in Kuwait. Wind Farmer, WAsP and Matlab still represent the most popular tools for some simulation stages to generate input data such as wind park conditions or farm layout configurations.

In this article, we present a work that deals with the configuration of a proposed wind farm at Kaberten. This work is based on two important points; at first, evaluation of the wind potential in the region to study, then, looking for the optimal capacity in number of turbines that must be installed in the proposed park. This last point is ensured by an optimal distribution of the wind turbines to reduce the effect of the wake and a number of wind turbines. In order to do this process, the WAsP software and the average speed 
data for the last 5 years in Kaberten are used. The simulation results of this work are obtained by introducing the characteristics of the GAMESA G2 wind turbine. The Jensen wake model and the mathematical approach that use the pseudorandom numbers [16] in a computer program developed in the Matlab environment.

\section{Wind resource assessments}

It is known that the distribution of the wind on the earth's surface is uneven, mean while, the landforms, the obstacles and the uneven warming by the sun's rays significantly modify the speed and direction of the wind on the sites. The wind potential of a site is defined as the extractable energy during a given period (typically 1 year) of operation for a given wind turbine on this site [17], since it is on it that the economic viability of a wind project is based. In order to quantify the wind park of such a region, it is necessary to have the distribution of the wind speed and direction on the site. In the southwest of Algeria, the Kaberten region of the Wilaya in Adrar has significant wind potential that allows to install a wind farm for electricity generation [14]. The hourly wind data (speed and direction) for each day, every month for 5 years are measured by the weather station at Adrar Airport [18]. These data are used in this study to estimate the efficiency, cost and cost per power unit as well as power production in the wind farm in relation to number of turbines in the wind farm.

The Weibull distribution is most suitable for the study of wind speed distribution. It is known that, the Weibull distribution is based on two important parameters, the form factor and the scale factor. The form factor $k$ which describes the fluctuations around the average speed is a dimensionless number, it accepts a value of 1 to 3 . A lower value would imply a very variable wind whereas a constant wind would imply a higher value $k$. While the scale factor expressed in $\mathrm{m} / \mathrm{s}$ is associated with the average wind speed, it can be used to determine the characteristic wind quality.

The frequency distribution of the wind speed is given by the following relation:

$f(v)=\left(\frac{k}{A}\right)\left(\frac{U}{A}\right)^{k-1} \exp \left(-\left(\frac{U}{A}\right)^{k}\right)$

where $k$ (non-dimensional) is a parameter related to the shape function and $A$ is the scale parameter very close to the average speed $U_{m}$. The calculation of these two parameters is in accordance with the following relations:

$k=\left(\frac{\sigma_{v}}{U_{m}}\right)^{-1.090}$
$A=\frac{2 U_{m}}{\sqrt{\pi}}$

At first point, the data used in this study, are based on WAsP and measurements of wind speed at $10 \mathrm{~m}$ from the ground by Adrar Airport weather station over a period of 5 years, i.e. from 2006 to 2010. The geographical coordinates of this station belonging to the ONM (National Office of Meteorology) are $27.82^{\circ} \mathrm{N}$ and $-0.18^{\circ} \mathrm{E}$.

The wind frequency distribution of the Kaberten region is presented by Fig. 1

The wind frequency distribution of the Kaberten region is presented by Fig. 1. As shown in this Figure, the Weibull curve of the Kaberten site reaches a maximum of $16 \%, 17.5 \%$ and $15 \%$ respectively for velocities, 5,6 and $7 \mathrm{~m} / \mathrm{s}$, then decreases as and when until it vanishes, so a total of $48 \%$ for this class of speeds. The average wind speed measured is $5.5 \mathrm{~m} / \mathrm{s}$, and since most wind turbines start at a wind speed of more than $3 \mathrm{~m} / \mathrm{s}$, the Kaberten site is favorable to the setting up of a park wind power for electricity generation.

In the wind rose shown in Fig. 2, the predominant directions are:

- North Direction-North East with a percentage of 15\%.

- North East-East direction with a percentage of $19 \%$.

- East direction with a percentage of $18 \%$.

As indicated in these results, it is advisable to install the wind farm in the middle of the predominant directions of wind speed which totals frequency of $52 \%$, and which is located in the direction North East-East.

Thus, the wind energy available at the Kaberten site can be calculated according to the relationship:

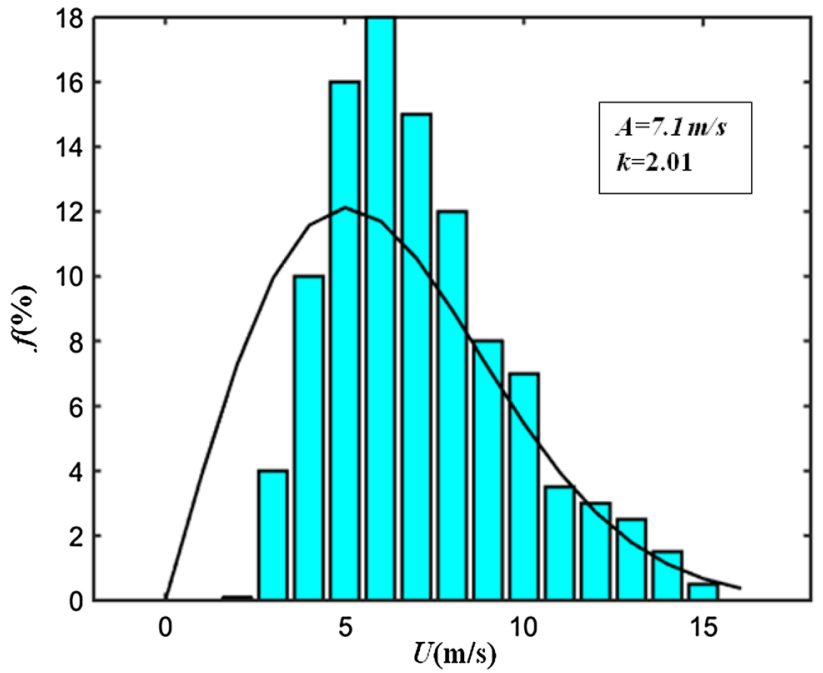

Fig. 1 Wind frequency distribution of the Kaberten region 


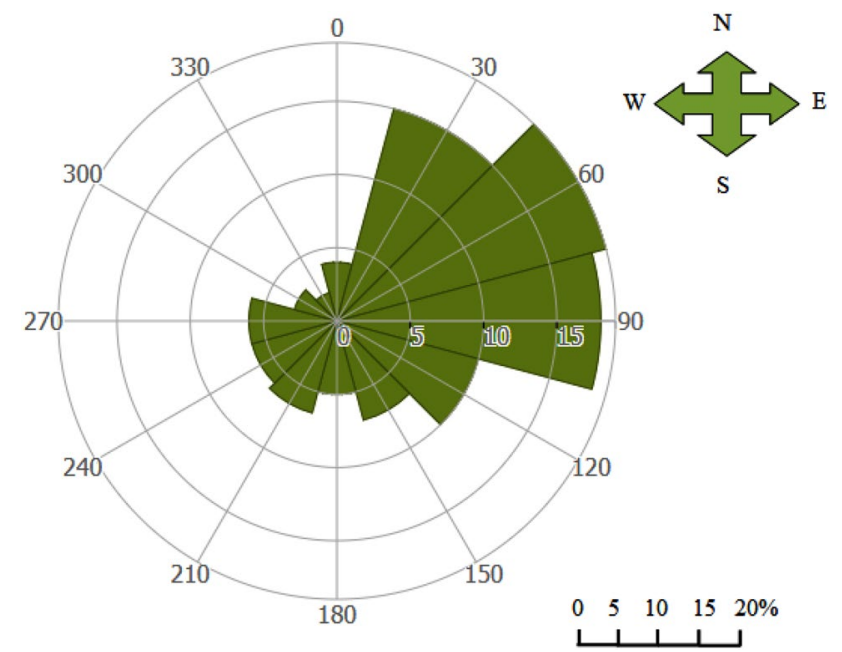

Fig. 2 Directional distribution of wind speeds of the Kaberten site

$P=\frac{1}{2} \rho A_{R} U^{3}$

where $U$ is the wind speed, $A_{R}$ is the surface of the turbine and $\rho$ is the density of the air.

\section{Wake model}

In 1983, Jansen [9] developed a simpler and more efficient wake model. This one is an analytical model that predicts the characteristics of the wake that evolves linearly. Its simplicity and ease of design with the programming tools (Matlab, $\mathrm{C}++$, Delphi). Jansen model is the subject of several uses in the optimal micro-location of the configuration of a wind farm by the codes such as WindPRO. Figure 3 illustrates the expansion of the wake on a horizontal plane through the hub of a turbine. The wake radius is given by the following relation as a function of the turbine radius $r_{0}$ and the position $x$ downstream of the wind turbine:

$r=\alpha x+r_{0}$

where a so-called drive constant, depending on the height $Z$ of the wind turbine and the roughness of the ground $Z_{O}$ is given by the relation [7]:

$\alpha=\frac{0.5}{\ln \left(\frac{z}{z_{0}}\right)}$

The wind speed in the wake is described by the relationship for a single turbine:

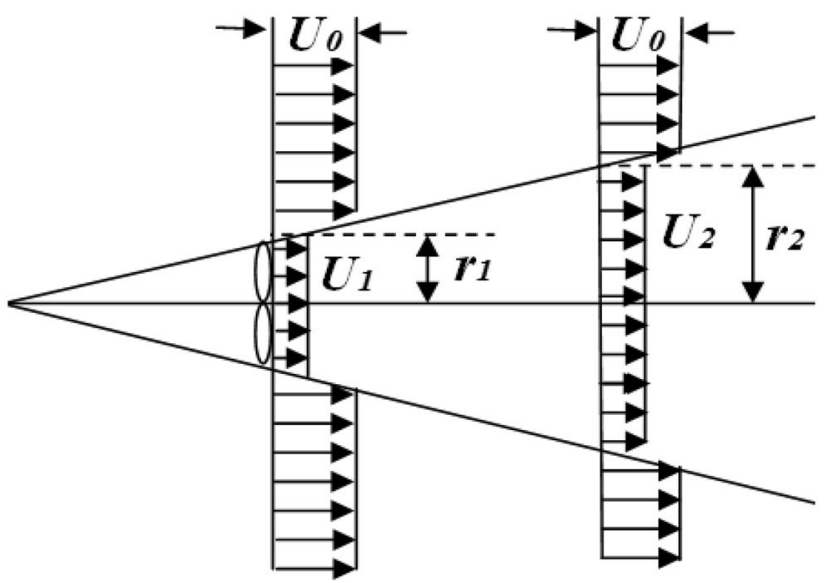

Fig. 3 Schematic of physical wake model

$U_{x}=U\left(1-\frac{R^{2}\left(1-\sqrt{1-C_{T}}\right)}{(R+\alpha x)^{2}}\right)$

In the case of a wind turbine affected by wakes of different turbines upstream, the resulting wake at a position $x$, is described by the principle of superposition. Thus, the speed at a distance downstream from a wind turbine can be written as follows according to Jensen's model [9]:

$U_{x}=U\left[1-\frac{r^{2}\left(1-\sqrt{1-C_{T}}\right)}{\sqrt{\sum_{i=1}^{N}\left(r_{0}+\alpha x\right)^{4}}}\right]$

\section{Wind farm configuration}

In the second configuration point of the wind farm, two procedures are developed and used. The first is based on the optimal positioning of wind turbines using the pseudo-random number generation approach to maximize energy production, and the second, on the minimal cost associated with a wind turbine installation.

\subsection{Pseudo-random numbers generation method}

Pseudo-Random Number Generation (PRN) is a mathematical approach that uses a mechanism to generate a sequence of pseudo-random numbers. Pseudo-random numbers (PRNs) can be found using in many fields; such as simulation process, cryptography and in several protocols requiring generation of random data [19]. The PRNs should, however, closely approximate the ideal properties 
of uniformity and independence in order to assure the randomness [20]. Based on our knowledge, this mathematical approach was introduced and used in a wind turbine optimization code by Zergane et al. [11], and was the subject of an international publication in 2018. The sequences generated by this method, are based upon the generators of pseudo-random numbers that often use recurrences in the form [21]:

$X(N+1)=(a X(N)+b) \bmod [m]$

\subsection{Optimization procedure}

The wind farm used for the optimization procedure is square-shaped terrain, subdivided into 100 identical cells. The center of each cell $(5 D \times 5 D$ size with $D$ is the diameter of the turbine) may be the possible location for a single turbine. The total park size is $50 D \times 50 D$ as shown in Fig. 4 .

The characteristics and the power curve of the GAMESA G52 turbine used in the simulation are shown in Table 1 and Fig. 5 respectively.

To determine the optimal result, the program developed in the Matlab environment (Fig. 6) is designed to compute and compare the recently obtained simulation results with previously saved optimal results. If the results of the last iteration are more optimal than those recorded, the program automatically saves the new results; otherwise, it deletes them. Then moves on to the next iteration. After passing through all the possible cases, the program gives us three results, the optimal capacity factor
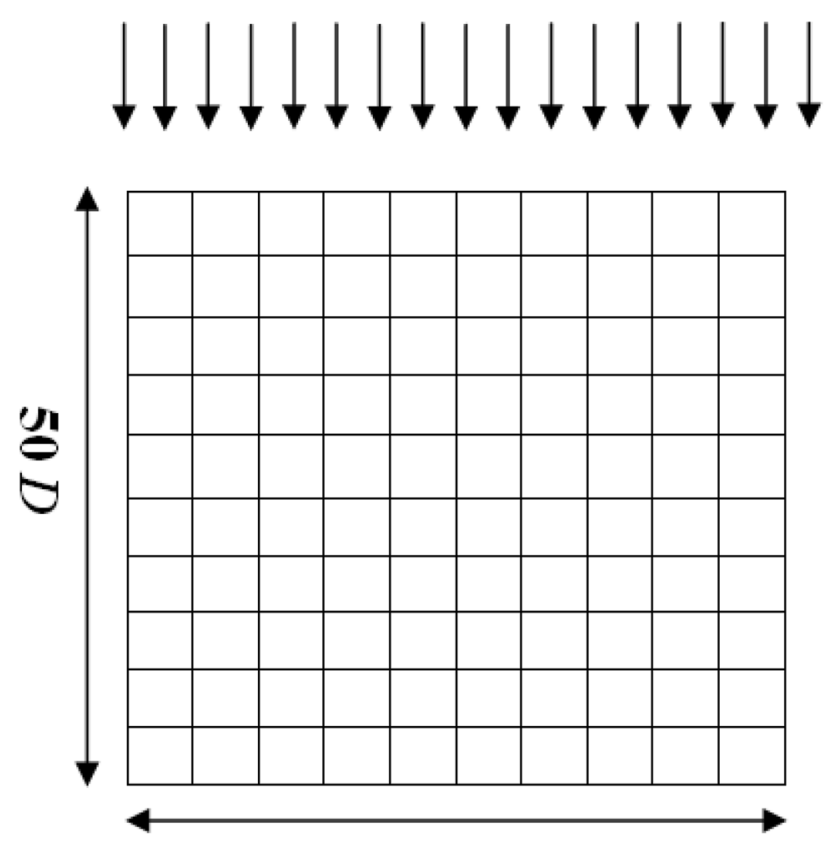

$50 D$
Table 1 Characteristics of the GAMESA G52 turbine

\begin{tabular}{ll}
\hline Designation & Value \\
\hline Length of the blade $\left(r_{0}\right)$ & $26 \mathrm{~m}$ \\
Rotor height $(Z)$ & $55 \mathrm{~m}$ \\
Rated power $(P)$ & $850 \mathrm{~kW}$ \\
\hline
\end{tabular}

(minimum value of the capacity factor), the appropriate number of turbines and the corresponding maximum power.

In order to calculate the optimal number of $N_{w t}$ wind turbines can be installed in the proposed park at Kaberten, the program illustrated in Fig. 6 is initialized by entering the required data, then Eq. (8) is introduced to generate the sequences (suites) of PRNs over several iterations. Each PRN of the generated suite is associated with a wind turbine for a single iteration that corresponds to a single arrangement. So the wind turbines are arranged in the park according to the PRNs that have been granted. After evaluating the wind speed for each turbine in the wake, the corresponding power $P(n)$, could be easily calculated, thus, the total power $P(m)$ of the GAMESA G52 turbines at each arrangement is only the sum of powers $(n)$. For such a number of wind turbines, the optimal location is obtained by the provision which gives a maximum power $P(m)_{\max }$. By varying the number of turbines, the optimal turbine capacity $\left(f_{o p}\right)$ to be installed in Kaberten Park, which represents the ratio the dimensionless cost of the wind turbine installation per unit of power, defined by Mosetti et al. [6] could be easily determined, it corresponds to the minimum value of the factor $f_{\text {cap }}$, this factor could be modeled as following:

$f_{\text {cap }}=\operatorname{Min}\left(\frac{\text { Cost }}{P_{\text {tot, } \max }}\right)$

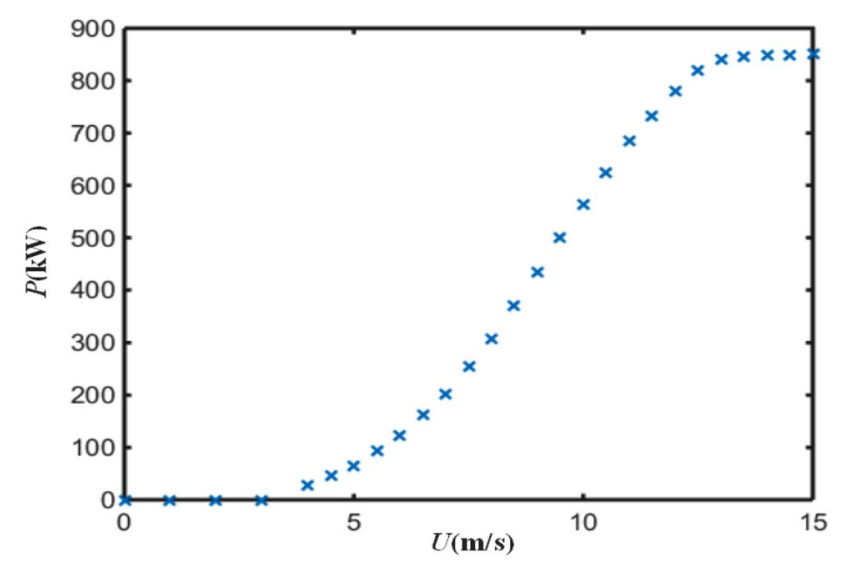

Fig. 5 Power curve of the GAMESA G52

Fig. 4 Proposed wind farm at Kaberten 
Fig. 6 Flowchart of the optimization method

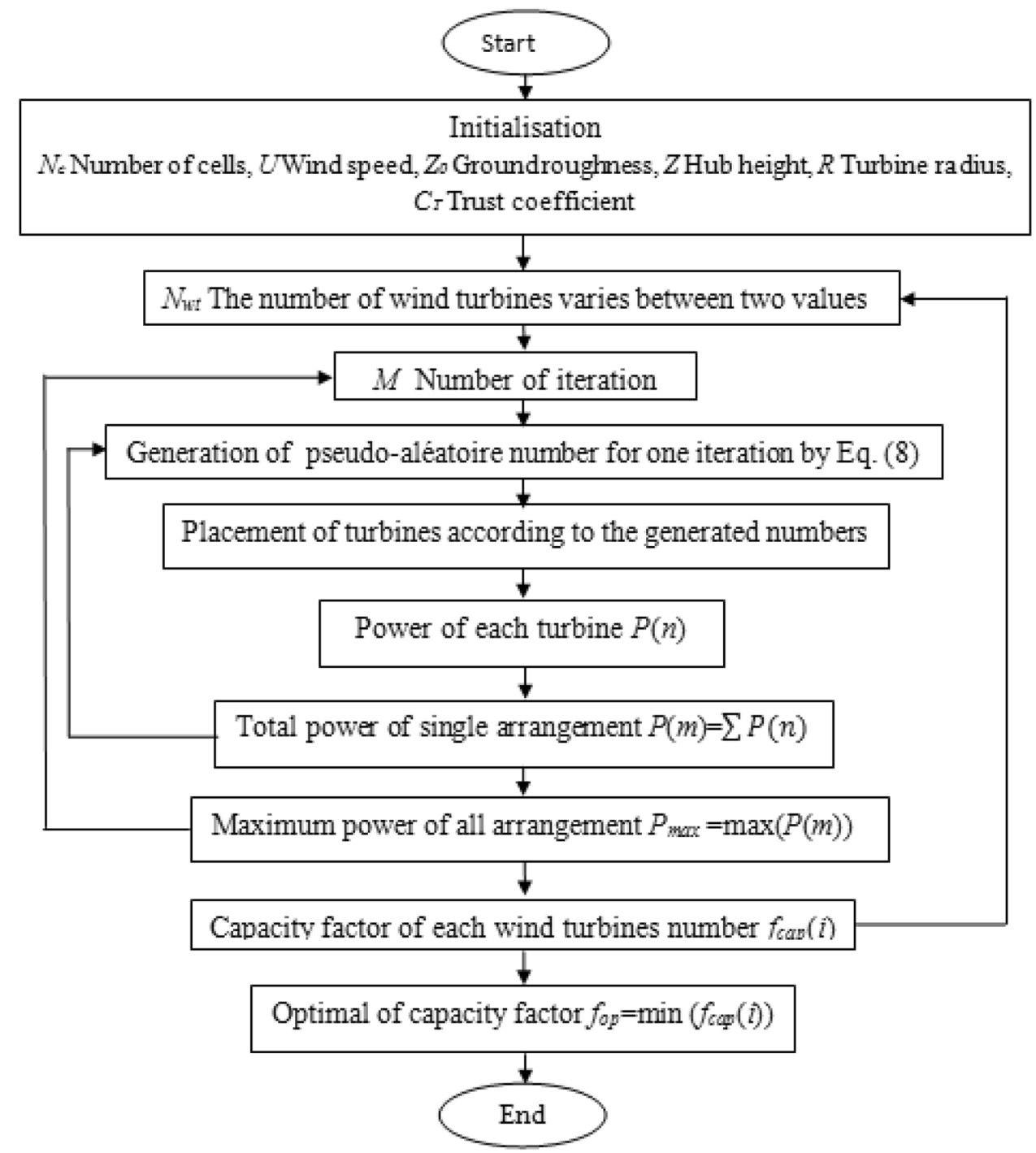

\section{Optimal capacity factor}

Under the conditions where the assumed ground roughness is $Z_{O}=0.3 \mathrm{~m}$ and the uniform and unidirectional wind velocity on the proposed Kaberten park, the optimal results obtained by the numerical simulation of several iterations offer a minimum capacity factor of 0.00889048 and a maximum power of $3.2277 \mathrm{MW}$, also, the appropriate number of turbines could be calculate, it corresponds to 42 wind turbines

The program developed under Matlab, also allowed us to obtain optimal positioning of these 42 turbines in the wind farm as shown in Fig. 7. The symbol $X$ represents the positions of the turbines in the proposed Kaberten site according to the wind farm in the predominant direction of the wind.
In this same figure, could be seen that a more extensive and more regular distribution between the wind turbines is obtained in the site, therefore, the interaction of the turbines is less important in the park.

\section{Conclusion}

This research work focuses on a configuration study of a proposed wind farm at Kaberten. Analysis based on WAsP software data and average 5-year wind speed show that the Adrar region has a significant wind potential, and may be the appropriate location for installation of a wind farm. For a given dimension of the proposed park, estimated that the optimal capacity in installed turbines reaches the number 42 in an optimal distribution. In order to achieve these optimal results, the Jensen 


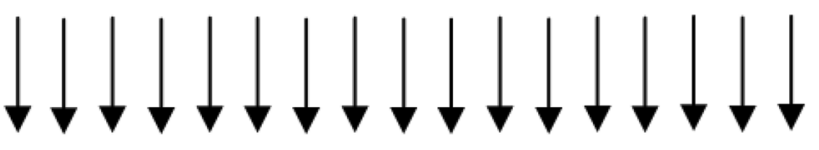

\begin{tabular}{|c|c|c|c|c|c|c|c|c|c|}
\hline & & & $\mathrm{x}$ & & & & & & \\
\hline & & & & $\mathrm{x}$ & $\mathrm{x}$ & $\mathrm{x}$ & $\mathrm{x}$ & $\mathrm{x}$ & $\mathrm{x}$ \\
\hline $\mathrm{x}$ & $\mathrm{x}$ & $\mathrm{x}$ & $\mathrm{x}$ & & & & & & \\
\hline & & & & & & & & & $\mathrm{x}$ \\
\hline $\mathrm{x}$ & $\mathrm{x}$ & $\mathrm{x}$ & $\mathrm{x}$ & $\mathrm{x}$ & $\mathrm{x}$ & $\mathrm{x}$ & $\mathrm{x}$ & $\mathrm{x}$ & \\
\hline & & & & & & & & & \\
\hline & & & & $\mathrm{x}$ & $\mathrm{x}$ & $\mathrm{x}$ & $\mathrm{x}$ & $\mathrm{x}$ & $\mathrm{x}$ \\
\hline $\mathrm{x}$ & $\mathrm{x}$ & $\mathrm{x}$ & $\mathrm{x}$ & $\mathrm{x}$ & & & & & \\
\hline & & & & & & & & & \\
\hline $\mathrm{x}$ & $\mathrm{x}$ & $\mathrm{x}$ & $\mathrm{x}$ & $\mathrm{x}$ & $\mathrm{x}$ & $\mathrm{x}$ & $\mathrm{x}$ & $\mathrm{x}$ & $\mathrm{x}$ \\
\hline
\end{tabular}

Fig. 7 Optimum location of turbines corresponds to minimum capacity factor

wake model and the characteristics of the GAMESA G52 turbine are introduced in an optimization program developed in the Matlab environment. The optimization method used in this work is based on the mathematical approach of generating pseudo-random numbers (PRNs) to predict the maximum power, the minimum capacity factor, and finally, the optimal matching arrangement. As a perspective of this work, planning in future studies to properly take into account the more complex terrain parks, all the components of the turbine and the turbulence of the flow.

\section{Compliance with ethical standards}

Conflict of interest The authors declare that they have no conflict of interest.

\section{References}

1. Snyder B, Kaiser MJ (2009) Ecological and economic costbenefit analysis of offshore wind energy. Renew Energy 34(6):1567-1578

2. Aras H, Erdoğmuş Ş, Koç E (2004) Multi-criteria selection for a wind observation station location using analytic hierarchy process. Renew Energy 29(8):1383-1392
3. Adaramola M, Krogstad P-Å (2011) Experimental investigation of wake effects on wind turbine performance. Renew Energy 36(8):2078-2086

4. Barthelmie RJ, Jensen $L$ (2010) Evaluation of wind farm efficiency and wind turbine wakes at the Nysted offshore wind farm. Wind Energy 13(6):573-586

5. Sarmast S, Chivaee HS, Ivanell S, Mikkelsen RF (2014) Numerical investigation of the wake interaction between two model wind turbines with span-wise offset. In: Journal of Physics: conference series, p 012137. IOP Publishing

6. Mosetti G, Poloni C, Diviacco B (1994) Optimization of wind turbine positioning in large windfarms by means of a genetic algorithm. J Wind Eng Ind Aerodyn 51(1):105-116

7. Grady S, Hussaini M, Abdullah MM (2005) Placement of wind turbines using genetic algorithms. Renew Energy 30(2):259-270

8. Marmidis G, Lazarou S, Pyrgioti E (2008) Optimal placement of wind turbines in a wind park using Monte Carlo simulation. Renew Energy 33(7):1455-1460

9. Jensen NO (1983) A note on wind generator interaction. Technical report. Riso-M-2411, Riso National Laboratory, Roskilde, Denmark

10. Mahulja S, Larsen GC, Elham A (2018) Engineering an optimal wind farm using surrogate models. Wind Energy 21(12):1296-1308

11. Zergane S, Smaili A, Masson C (2018) Optimization of wind turbine placement in a wind farm using a new pseudo-random number generation method. Renew Energy 125:166-171

12. Pérez B, Mínguez R, Guanche R (2013) Offshore wind farm layout optimization using mathematical programming techniques. Renew Energy 53:389-399

13. Wang L, Tan AC, Cholette M, Gu Y (2016) Comparison of the effectiveness of analytical wake models for wind farm with constant and variable hub heights. Energy Conversat Manag 124:189-202

14. Mohamed B, Fadela B, Mounir K (2015) Optimization of the wind turbines location in Kaberten wind farm in Algeria. Energy Proc 74:122-129

15. Gharbia Y, Anany M (2016) Feasibility study of erecting a wind farm in Kuwait. In: ASME 2016 international mechanical engineering congress and exposition, American Society of Mechanical Engineers

16. Bouleau N, Bensoussan A (1986) Probabilités de l'ingénieur: variables aléatoires et simulation. Hermann, Paris

17. Fichaux N, Poglio T, Ranchin T (2005) Mapping offshore wind resources: synergetic potential of SAR and scatterometer data. IEEE J Ocean Eng 30(3):516-525

18. Merdaoui M, Houha A, Smaïli A (2010) Etude et dimensionnement du futur parc éolien de Kaberten situé dans la région d'Adrar. Rev Energ Renouv 10:269-274

19. Nagaraj N, Shastry MC, Vaidya PG (2008) Increasing average period lengths by switching of robust chaos maps in finite precision. Eur Phys J Spec Top 165(1):73-83

20. Wangdee W (2005) Bulk electric system reliability simulation and application. Citeseer

21. Li W (2014) Risk assessment of power systems: models, methods, and applications. Wiley, Hoboken

Publisher's Note Springer Nature remains neutral with regard to jurisdictional claims in published maps and institutional affiliations. 